\title{
Wellness programs and means of getting employees to stay healthy: a response to Kristin Van Busum and Soeren Mattke
}

\author{
Bahaudin G. Mujtaba ${ }^{\star}$, Frank J. Cavico
}

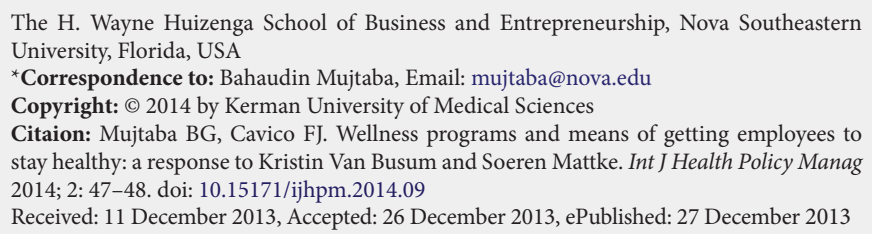

The H. Wayne Huizenga School of Business and Entrepreneurship, Nova Southeastern University, Florida, USA

*Correspondence to: Bahaudin Mujtaba, Email: mujtaba@nova.edu

Copyright: $\odot 2014$ by Kerman University of Medical Sciences

Citaion: Mujtaba BG, Cavico FJ. Wellness programs and means of getting employees to stay healthy: a response to Kristin Van Busum and Soeren Mattke. Int J Health Policy Manag 2014; 2: 47-48. doi: 10.15171/ijhpm.2014.09

Received: 11 December 2013, Accepted: 26 December 2013, ePublished: 27 December 2013

$\mathrm{T}$ This is a short writing in response to the "Financial Incentives: Only One Piece of the Workplace Wellness Puzzle" (1) by Kristin Van Busum and Soeren Mattke of the RAND Health Advisory Services, RAND Corporation, in Boston.

We would like to thank Kristin Van Busum and Soeren Mattke for their time in reading our article and offering excellent suggestions to employers and policymakers in order to make workplace wellness programs more successful for all employees. We agree that offering financial incentives is just one "piece of the puzzle" for employers as they contemplate strategies to effectively deal with this "giant elephant in the boardroom." It is good to see that there is agreement on the urgent need for addressing chronic illnesses in the workplace along with reducing the spiraling healthcare costs.

Our article entitled "Corporate Wellness Programs: Implementation Challenges in the Modern American Workplace" (2) was limited in its scope; and consequently only offered a discussion on rewards "carrots" versus penalty-based "sticks", incentives for participation in corporate workplace wellness programs along with an examination of some of the legal considerations that govern those incentives in the United States. The article did make mention of health risk assessments, stress management, smoking cessation, and other programs that are not always based on financial rewards or penalties, but naturally can be helpful for employees, employers, and society in general. We do like Kristin Van Busum and Soeren Mattke's suggestion of creating a "wellness culture" throughout the organization; such a culture is an excellent way to get everyone to automatically make healthy choices based on the socialization and peer group conduct that can come with such a "healthy" environment. There are many ways to develop such an organizational culture for behavior management; nevertheless, such an approach can also be criticized as the manipulation and even "brainwashing" of employees, thereby removing the option of making a "free" personal choice for themselves. The idea of "peer pressure" or "social pressure" is naturally a reality in every workplace; but then so is intimidation or even "bullying," which clearly is not encouraged or formalized by employers.

As educators, authors, and practitioners, we have trained thousands of corporate and public sector managers in the United
States and abroad; but we have not seen any firms to institute peer pressure as a formal element of its wellness program. Since we are both in favor of having a strong work culture, effective corporate training programs, and creating an organizational culture that is focused on legal, ethical, and efficacious choices, we advocate the development of comprehensive wellness awareness programs. Yet, we cannot fully advocate peer pressure or social pressure as one of the tactics since such "pressure" has negative implications, and moreover, the field is beyond the scope of our main areas of research and practice. Nevertheless, we are advocates of developing positive reinforcement strategies in order to bring about positive behavioral changes in the health choices of employees in the modern workplace.

In our article, we tried to emphasize that one initial problem with any examination of wellness programs in the workplace is that there is no statutory, regulatory, or uniform definition of the term "wellness program." Furthermore, there is no single definition of a "wellness program." One general definition would mean programs that are sponsored by an employer that seek to improve the physical and/or mental health of employees. Nonetheless, as most researchers have already agreed, a universally agreed-upon definition of a workplace wellness program is not available yet, particularly since most employers manage their programs based on their employees' needs, their resources, and local challenges. Accordingly, employers should have the discretion in formulating wellness programs based on financial and non-financial rewards as relevant for their organizations, departments, employees, available resources, and of course legal requirements in locations where the firm is operating. All wellness programs tend to have an educational component that seeks to inculcate the employees to the benefits of a healthy lifestyle, and thus to increase the awareness of how lifestyle choices can impact one's physical and mental health. Common features of wellness programs can encompass providing healthcare and medical information by means of health fairs, seminars, classes, lectures, and newsletters; online health and wellness resources; nutrition counseling; lifestyle and risk factor analysis; health and exercise coaching; gym and health club memberships or membership discounts; heath risk assessments; stress management programs; disease management and control programs (concerning heart disease, diabetes, blood pressure, for example); biometric testing and screening, maintenance, and control for heart disease, blood pressure, hypertension, cholesterol, and weight loss; smoking cessation programs; immunization programs; and on-site clinics.

While our article was focused on healthcare challenges in the United States, but now many other firms across the globe are 
facing similar challenges. As such, the concepts and suggestions are equally beneficial for all policymakers and employers who want to keep their employees healthy and their insurance costs down. Naturally, the U.S. legal components would not apply to foreign countries as each country would have its own laws and procedures.

The reality is that we well know that employers around the globe definitely want lower health insurance costs and more productive employees; and one way to achieve these goals is to have healthier employees. The question, and one with legal, ethical, and practical ramifications, is how to attain these laudable objectives. Should the employer in adopting a wellness policy take a voluntary "carrot" or a more coercive "stick" approach? Should employees who adopt healthy lifestyles be rewarded? Or should employees who lead unhealthy lifestyles be penalized by the employer? In some wellness programs, an overweight or smoking employee may have to confront certain "sticks," for example, higher monthly healthcare premiums and no discounts if the employee does not avail himself or herself of the wellness program. Regarding the "sticks" approach, some studies note that these programs imply that individuals making poor health decisions should not have their "bad" choices or decisions subsidized through a group insurance policy paid for in part by those making healthier decisions. Of course, as Kristin Van Busum and Soeren Mattke well advise, employers should review all possible options, and not just financial rewards and penalties, as they consider the best means to achieve a healthy workplace and workforce in a legal, ethical, and effective manner.

\section{Ethical issues}

Not applicable.

Competing interests

The authors declare that they have no competing interests.

Authors' contribution

Both authors equally contributed to the writing of this article.

\section{References}

1. Van Busum K, Mattke S. Financial incentives: only one piece of the workplace wellness puzzle; Comment on "Corporate wellness programs: implementation challenges in the modern American workplace". Int J Health Policy Manag 2013; 1: 311-2.

2. Mujtaba BG, Cavico FJ. Corporate wellness programs: implementation challenges in the modern American workplace. Int J Health Policy Manag 2013; 1: 193-9. 